\title{
Wear Analysis on Piston
}

\author{
Parmar Bhavin $\mathbf{R}^{1}$, Patel Jenish $\mathbf{C}^{2}$, Mistry Komal $\mathbf{J}^{3}$, Sompura Mayank ${ }^{4}$ \\ ${ }^{1,2,3}$ Student of Mechanical Engineering, Valia Institute of Technology, Bharuch, Gujarat Technological University, India
}

${ }^{4}$ Head of Mechanical engineering Department, Valia Institute of Technology, Bharuch, Gujarat Technological University, India

\begin{abstract}
The tribological phenomenon of the sliding surface between piston rings and cylinder liner may be among the most complex in internal combustion engine and could become even more severe with an increase of the engine power. The friction between the piston rings and the cylinder liner significantly contribute to the mechanical power losses of the engine. Improvement of the fuel economy of automobile is gaining increasing importance today. This project the assembly and development of a test rig for the measurement of friction in a reciprocating system. In this test rig a flat plate (specimen) is located in an aluminium oil bath and reciprocated under a loaded point ended pin. A crankshaft with the use of connecting rod gives the reciprocating movement of oil bath. In this testing an external 3-phase of 0.25 HP. Capacity is selected for testing purpose. In the setup we have used connecting rod crank shaft assembly, sliding aluminum oil bath have a rectangular shape, $v$ belt, pulley, flat plate (specimen) of brass and Aluminum, manufactured studs, fixed supports friction free trolley, extension of crank shaft, support for the whole set up. The experimental setup is assembled and the experimental will be conducted for measurement of friction pin and plate and also measure the wear rate of the flat plate.
\end{abstract}

Keywords: Wear, Piston, Lubrication, Friction, Analysis

\section{Introduction}

\subsection{Friction}

Friction is the force resisting the relative motion of solid surfaces, fluid layers, and material elements sliding against each other.

\subsubsection{Law of Friction}

\section{Law 1}

When two bodies are in contact the direction of the forces of Friction on one of them at its point of contact, It is point of contact is opposite to the direction in which the point of contact tends to move relative to the other.

\section{Law 2}

If the bodies are in equilibrium, the force of Friction is just sufficient to prevent motion and may therefore be determined by applying the conditions of equilibrium of all the forces acting on the body.

The amount of Friction that can be exerted between two surfaces is limited and if the forces acting on the body are made sufficiently great, motion will occur. Hence, we define limiting frictions the friction which is exerted when equilibrium is on the point of being broken by one body sliding on another. The magnitude of limiting friction is given by the following three laws.

\section{Law 3}

The ratio of the limiting friction to the Normal reaction between two surfaces depends on the substances of which the surfaces are composed, and not on the magnitude of the Normal reaction.

This ratio is usually denoted by $\mu$.

Thus if the Normal reaction is $\mathrm{R}$, the limiting friction is $\mu R$
For given materials polished to the same standard $\mu$ is found to be constant and independent of $\mathrm{R}$.

\subsubsection{Classification of Friction}

\section{Sliding friction:}

When two bodies slip on a surface the force resisting the motion is known as sliding friction.

\section{Rolling friction:}

When a body on surface a force resisting its motion is known as rolling friction. Rolling element such as belt drive are the ex. for rolling friction. In the case of contact rolling friction real area of contact is much less the in case of sliding friction. Therefore co-efficient of rolling is less than coefficient of sliding.

\subsection{Wear}

Wear has been defined as either mass of volume of material removed or displaced from a body which is repeatedly stressed in mechanical contact with another body. Due to wear mechanical loading increased by decreasing volume \& also increase clearance between moving components which may result in failure of components.

\subsection{Lubrication}

An integral part of design engineering is a consideration of what happens at the interface between touching components. If the surfaces are in close proximity then peaks of surface asperities interact \& increase friction.

Lubrication is a process of applying and milling friction modifier, which reduces friction and wear by separating the contacting surfaces and also remove heat produce by friction. To reduced down the possibility of breakage and to modify the friction some additives are added in between mating surface, which is known as friction modifier or lubricants. 


\section{International Journal of Science and Research (IJSR) \\ ISSN (Online): 2319-7064 \\ Index Copernicus Value (2013): 6.14 | Impact Factor (2015): 6.391}

\subsubsection{Function of Lubrication}

Lubricants have to do several jobs due to irregularities on this surface, dry or solid friction is produced. It creates large amount of heat resulting in wear and power losses lubricants make a viscous layer around this surfaces and considerably reduced friction.

Beside lubricating and removing heat itself to absorbs shocks between bearing and seal the space between two surfaces. Lubrication provides smooth motion in case of bearing and also provides easier displacement. Lubricants may come in three forms.
a) Liquid
b) Solid
c) Semi liquid

\section{Working}

A pin on plate test machine has been developed to simulate to simulate the friction and wear mechanism encountered between the sliding surfaces.

A schematic diagram of the main features of the test rig is below given. A flat plate (specimen) is located in an aluminum oil bath and reciprocated under a loaded flatended pin. The sliding speed is controlled to produce a wear to produce a wear track length. For each test fresh samples of wear pin and plate wear assembled in the test machine and oil of the test lubricant added to the oil bath. The bath was heated to the required temperature and allowed to stabilize. The pin was then lowered carefully on the reciprocate and test load applied.

The parameter of friction, wear and temperature were continuously monitored throughout each test. Furthermore the weight loss of the specimen was also measured. At the completion of the test, the wear pin was raised of the reciprocating plate before stopping the drive motor. The test samples were removed degreased and weighted properly.

\section{Motor}

An electric motor is an electromechanical device that converts electrical energy into mechanical energy.

Most electric motors operate through the interaction of magnetic fields and current-carrying conductors to generate force. The reverse process, producing electrical energy from mechanical energy, is done by generators such as an alternator or a dynamo; some electric motors can also be used as generators, for example, a traction motor on a vehicle may perform both tasks. Electric motors and generators are commonly referred to as electric machines.

Speed of motor $1400 \mathrm{rpm}, 0.25 \mathrm{hp}$ and 180 watt with A.C uses.

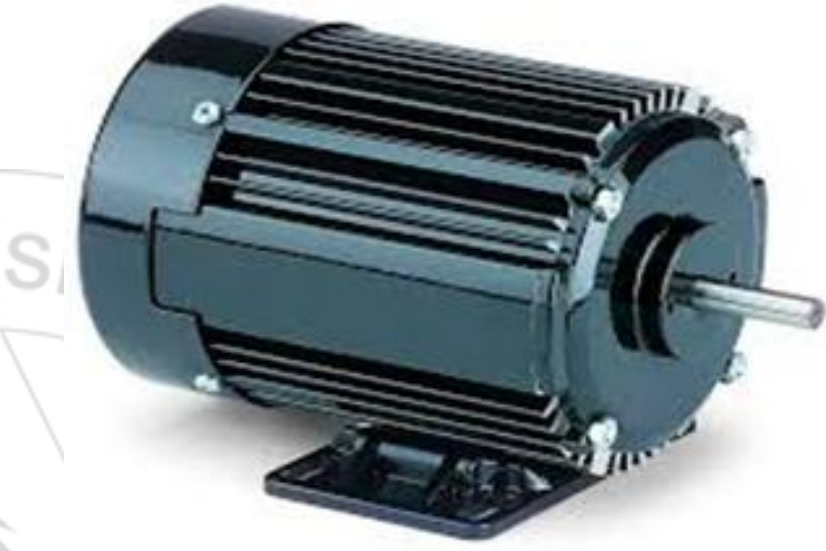

Figure 2:

\section{Crank Shaft}

The crankshaft, sometimes abbreviated to crank, is the part of an engine that translates reciprocating linear piston motion into rotation. To convert the reciprocating motion into rotation, the crankshaft has "crank throws" or "crankpins", additional bearing surfaces whose axis is offset from that of the crank, to which the "big ends" of the connecting rods from each cylinder attach.

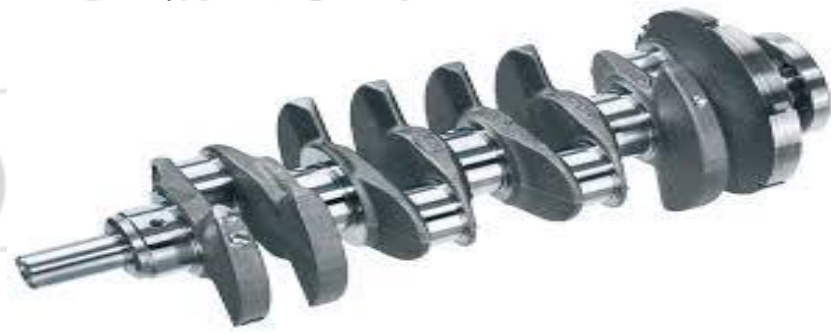

Figure 3:

Speciman

Using two types of materials of specimen.

- Brass

- Aluminum

\section{Tachometer}

Tachometer, it is contact type tachometer. It is used for the measuring speed of rotating equipment. There are two type of measuring instrument. Tachometer which is contact type tachometer and stroboscope which non- contact type instrument.

- Motor

- Crank Shaft

- Specimen

- Oil Bath

- Pin

- Techometer

- LVDT 


\section{International Journal of Science and Research (IJSR) \\ ISSN (Online): 2319-7064}

Index Copernicus Value (2013): 6.14 | Impact Factor (2015): 6.391

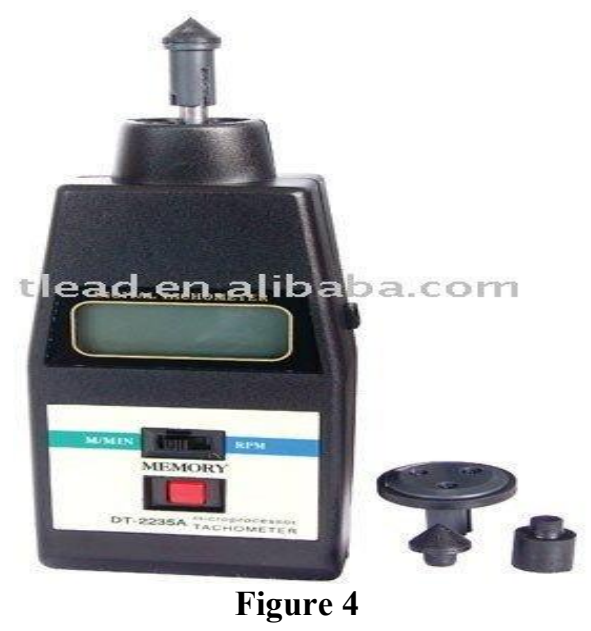

LVDT (linear variable differential transformer):

The linear variable differential transformer (LVDT) (also called just a differential transformer is a type of electrical transformer used for measuring linear displacement (position).

The linear variable differential transformer has three solenoid coils placed end-to-end around a tube. The center coil is the primary, and the two outer coils are the top and bottom secondaries.

A cylindrical ferromagnetic core, attached to the object whose position is to be measured, slides along the axis of the tube.

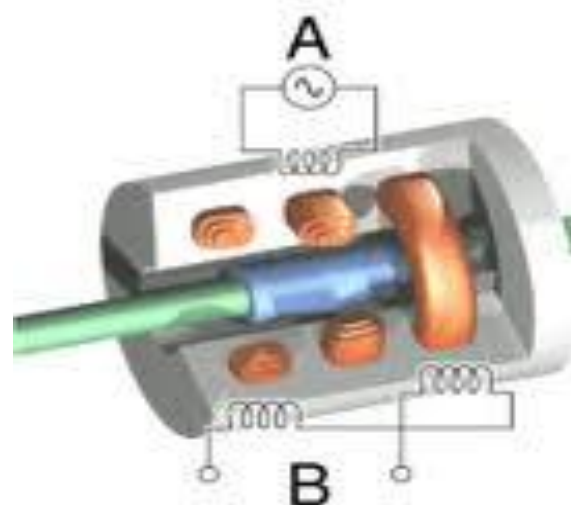

Figure 5

\section{PIN}

Material of pin is stainless steel.

Length of pin $25.9 \mathrm{~cm}$

Diameter of pin $0.7 \mathrm{~mm}$

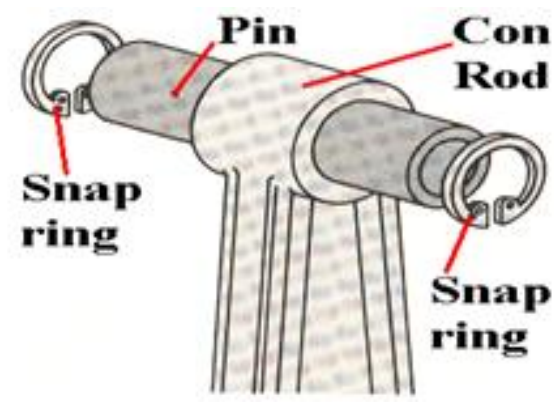

Figure 6

\section{Result}

\section{Oil: Without oil}

Material of specimen: Aluminum, Brass.

Material of pin: Stainless steel

GRAPH: - WEAR RATE (gm) VS TIME (min)

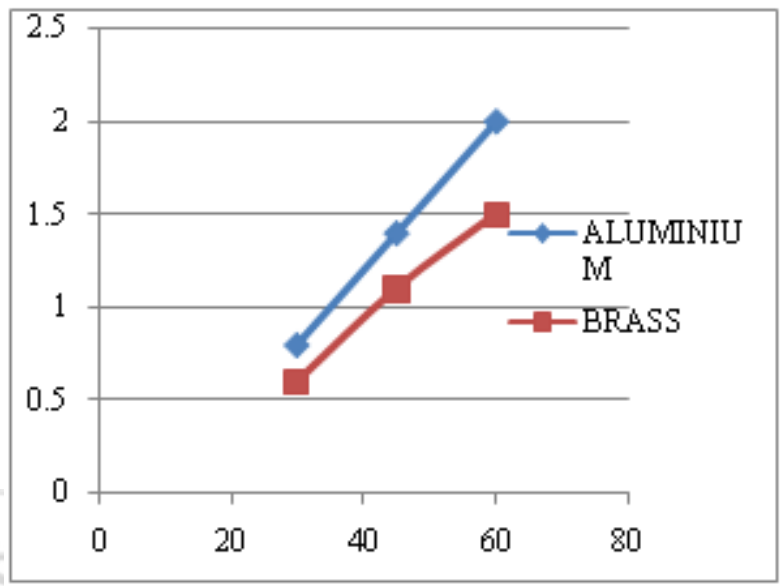

2. Lubrication Oil:-SAE 20W40

SPEED: - $455 \mathrm{rpm}$

GRAPH:-WEAR RATE (gm) VS TIME(min)

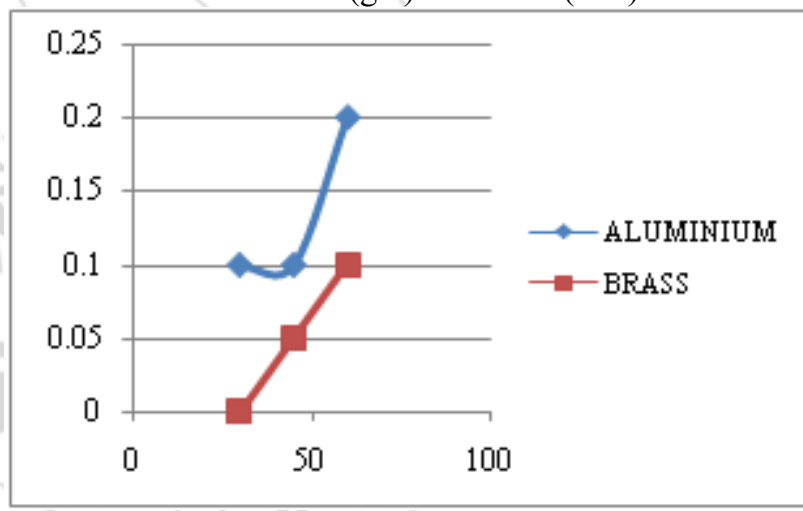

3. Lubriction Oil: - SAE 20W40 MOTOR SPEED: - 350RPM

GRAPH: - WEAR RATE (gm) VS TIME (min)

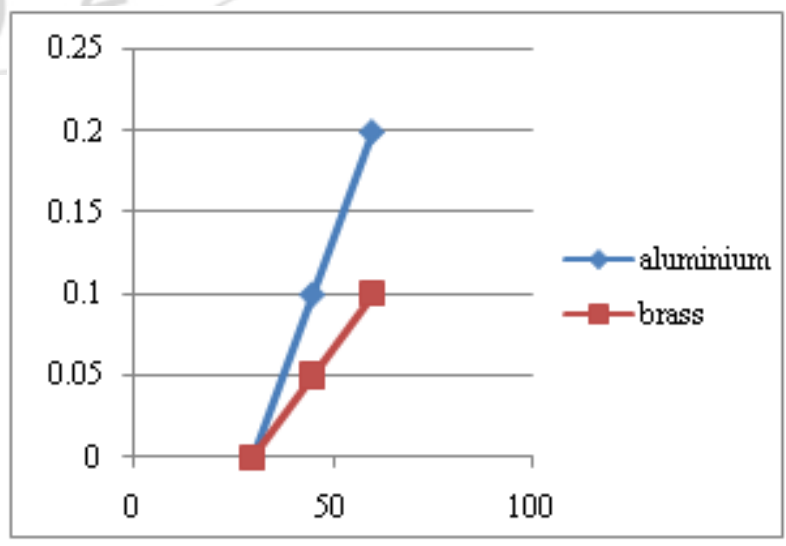

4. Lubrication Oil:-SAE 15W20

SPEED:-455 RPM

GRAPH: - WEAR RATE (gm) VS TIME (min) 


\section{International Journal of Science and Research (IJSR) \\ ISSN (Online): 2319-7064}

Index Copernicus Value (2013): 6.14 | Impact Factor (2015): 6.391

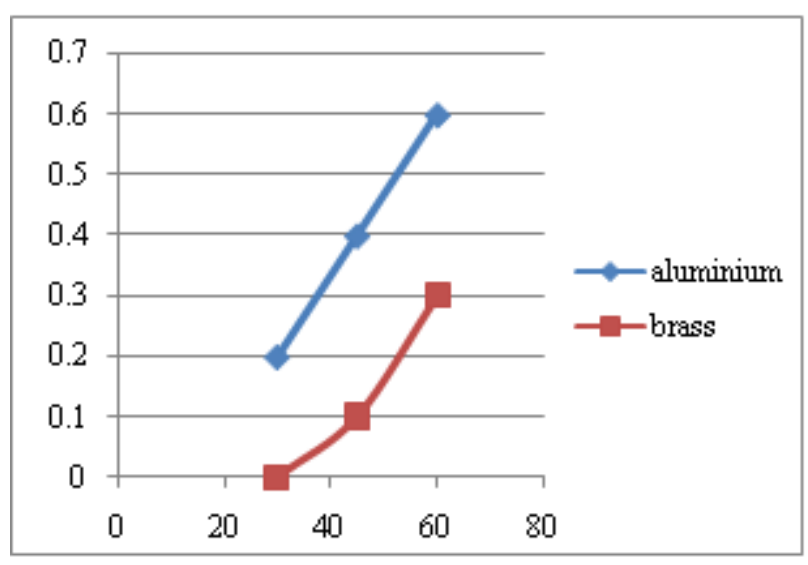

[6] This project was conducted in SVRCET in 2000.

[7] Smith C. A and Davis " Wear of piston ring and cylinder bore materials"' Automobile Eng. 1984.

[8] Eyre T.S., Dutta K.K and Davis F.A, characterization and simulation of wear occurring in the bore of the internal combustion engine.

[9] Parker D. A and Adams D. R, Frictional losses in the reciprocating internal combustion engine.

[10] Nadel J. and Eyret T. S, cylinder liner wears in low speed diesel engine Tribology. Int., 1978,11.

5. Oil: - SAE $15 \mathrm{~W} 20$

SPEED:-350 RPM

GRAPH: -WEAR RATE (gm) VS TIME (min)

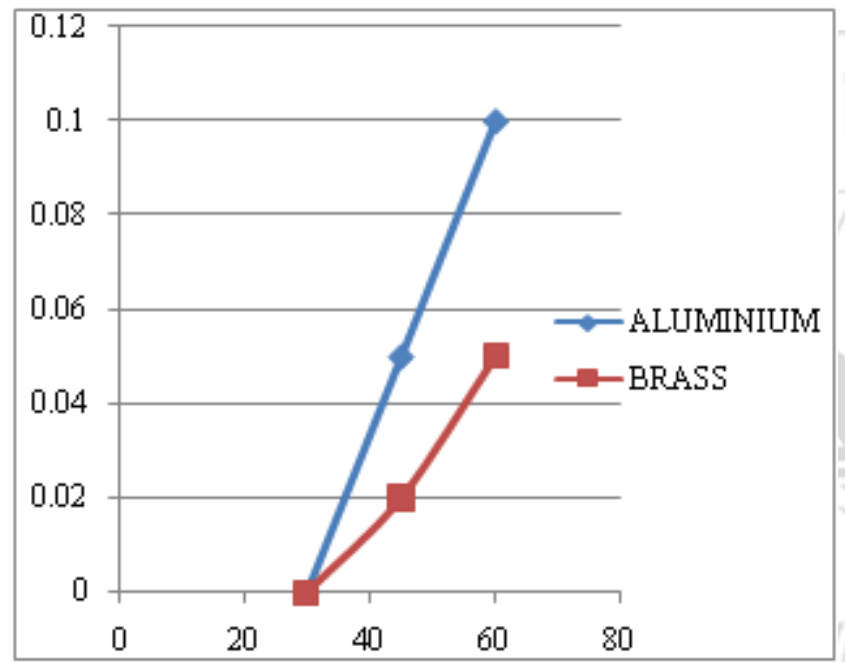

\section{Conclusion}

- Without lubricant there is increased in wear rate than using of lubrication

- When SAE 15W20 oil is used as a lubricant then the wear rate is found to be increasedthan SAE 20W40 oil

- The amount of wear rate increased with the increasing in speed.

- Also the Brass specimen shows high wear rate than aluminum because of low wear resistance property of brass compare to aluminum.

\section{References}

[1] Waurika and Hematake, 'Piston ring Friction in Internal Combustion Engine, Tribology international, 1992, vol-25.

[2] M. Hoshi, " Reducing friction Losses In Automobile Engines" Tribology international.

[3] John B. Heywood, "Internal Combustion Engine Fundamentals" McGrawhill international edition.

[4] R. S. Khurmi," Theory of Machines", S. Chand publication

[5] Yukio Tateishi, 'Tribology issues in Reducing Piston ring Friction 'Losses", Tribology internation 1994, vol27. 